\title{
INTERFEROMETRIC CONTROL FOR MAPPING AND QUANTIFYING THE 2012 BREAKUP OF MATUSEVICH ICE SHELF, SEVERNAYA ZEMLYA
}

\author{
Aleksey Sharov ${ }^{(1)}$, Dmitry Nikolskiy ${ }^{(2)}$, Ksenia Troshko ${ }^{(3)}$ and Zinaida Zaprudnova $^{(3)}$ \\ (1) DIGITAL - Joanneum Research, Steyrergasse 17, 8010 Graz, Austria, Email: aleksey.sharov@joanneum.at \\ (2) Sovzond, Shipilovskaya 28 A, Moscow, 115563, Russia, Email: nikolskiy@inbox.ru \\ (3) Faculty of Geography, Lomonosov Moscow State University, Lenin Mountains 2, 119992, Russia
}

\begin{abstract}
ERS, TDX and S1A SAR interferometric models calibrated with ICESat and CryoSat-2 altimetry data were successfully applied to mapping and quantifying recent breakup of the Matusevich Ice Shelf in Severnaya Zemlya. The assessment of the mapped changes showed that the ice shelf lost $123 \pm 2.5$ $\mathrm{km}^{2}$ or two thirds of its area and $9 \pm 0.3 \mathrm{~km}^{3}$ of its volume in the course of the past 5 years. The potential causes and aftereffects of the ice shelf disintegration were determined and the sensitivity of MIS remnants to climatic forcing was assessed. The mean annual temperature of $-9^{\circ} \mathrm{C}$ proved to be a valid climatic threshold for the ice-shelf viability in the Russian Arctic. We suggest that the integral estimation of calving regime in Severnaya Zemlya previously published by other investigators is out-of-date and must be revised.
\end{abstract}

\section{INTRODUCTION}

Permanent floating extensions of grounded glaciers referred to as ice shelves belong to relatively uncommon, rapidly vanishing and poorly documented forms of present-day glaciation in the Arctic [1]. According to Wikipedia ice shelves are only found in Antarctica, Greenland and Canada (2015). This message is rather misleading, however, as it disregards the existence of ice shelves in the Russian High Arctic. The largest of Russian ice shelves, the Matusevich Ice Shelf (MIS) in Severnaya Zemlya, $241 \mathrm{~km}^{2}$ in size (1953), lies south of $80^{\circ} \mathrm{N}$ thus being the southernmost floating glacier in the Old World. All Canadian ice shelves at Ellesmere Island are situated north of $82^{\circ} \mathrm{N}$.

The recent series of ice shelf collapses in West Antarctica, Greenland and Canadian Arctic raised, apart from the discussion on their potential causes, a question about the validity of empirical climatic thresholds established somewhat earlier for the ice-shelf viability in different geographic settings and epochs [2, 3, 4 and 5]. In this regard, MIS represents a unique object for studying ice-shelf behaviour and stability of parent ice masses in glaciomarine environments, which are dynamically different from those in the West. MIS is several orders smaller than ice shelves in the Antarctica and Greenland and is, sometimes, referred to as "natural model" of larger floating glaciers [6]. MIS is the main producer of large tabular icebergs up to several kilometres in size threatening ships and oil rigs in the Laptev and Kara seas. Its breakup in 2012 exited debates about the emergence of new icebergs and gave a new impetus to glaciological research and remote sensing activities in and around Severnaya Zemlya.

Joanneum Research in Graz has been conducting detailed remote sensing studies of MIS and parent ice caps using a synergetic combination of satellite altimetry and interferometry as a part of the 5-year programme of glacier change mapping in Severnaya Zemlya carried out since 2009 [7]. The present paper describes a new series of glacier interferometric models and satellite image maps at 1:100,000 scale representing the current state of the ice shelf and demonstrating dynamic changes in its topography and rheology in the past 80 years. The quantitative characteristics of main calving events and associated ice loss processes derived from space-borne ERS, TanDEM-X, CryoSat and Sentinel-1 radar data, WorldView, LANDSAT and ICESat optical data are validated and interpreted by comparing with 30-year-old cartographic reference models, air-borne radio-echo sounding data and 30year-long hydrometeorological and oceanographic time series. The potential causes and collateral effects of the ice shelf disintegration have been determined and the sensitivity of MIS remnants to climatic forcing has been assessed.

\section{GEOGRAPHICAL SITUATION}

MIS $\left(79.8^{\circ} \mathrm{N}, 98.0^{\circ} \mathrm{E}\right)$ is a confluent ice shelf formed by 8 outlet glaciers which flow down from Rusanov Ice Cap $\left(956 \mathrm{~km}^{2}\right)$, at the north, and Karpinsky Ice Cap $\left(2561 \mathrm{~km}^{2}\right)$, at the south, into the 50-km-long Matusevich Fjord situated on the northern coast of October Revolution Island in the Severnaya Zemlya archipelago [8]. These glacier tongues merge and build a platform of floating ice with seemingly flat and smooth albeit fissured surface. Gently sloping surface of the ice platform with typical slopes of $0.2^{\circ}$, large depths in the fjord, continuous propagation of internal tides between the outer and the inner parts of the fjord, periodic release of large tabular icebergs and the results of multitemporal remote sensing studies and geodetic works provide the evidence that the ice shelf is largely afloat [6]. The floating state of MIS was accepted by all investigators from the very beginning of its explorations [9].

The Matusevich Fjord provides very favourable conditions for the ice shelf viability (Fig.1, a). Owing to 
its north-eastward orientation, the ice shelf is secluded from strong insolation and is well protected from the impact of winds and waves of the Laptev Sea. Several small islands and banks support MIS in its central and widest part. Water depths range from $323 \mathrm{~m}$ in the fjord mouth to $258 \mathrm{~m}$ twelve kilometres inwards, decreasing to $50 \mathrm{~m}$ between Arduous and Barrier islands and increasing again to $128 \mathrm{~m}$ in front of Cape Fort, $17 \mathrm{~km}$ upstream. Radio-echo soundings (RES) of 1968/69 and $1974 / 75$ showed the potential existence of large depths exceeding $200 \mathrm{~m}$ beneath the south-eastern part of MIS [8]. The bottom profile in other parts remains uncertain.
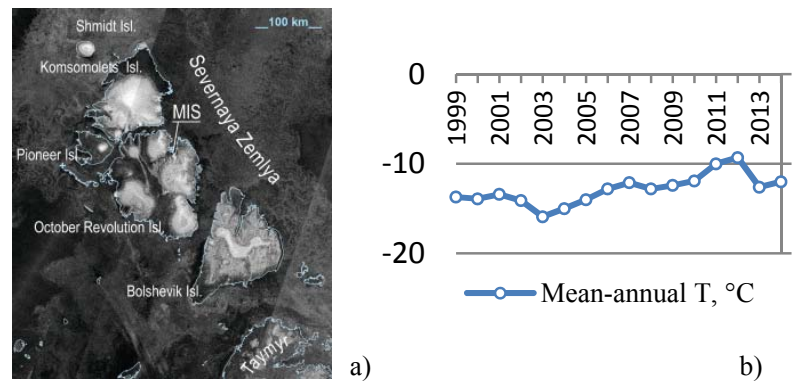

$\longrightarrow$ Mean-annual $\mathrm{T},{ }^{\circ} \mathrm{C}$

a)

b)

Figure 1. Location diagram (Sentinel mosaic, a); mean annual temperature at Golomyanny Island $(b,+$ in $a)$

The shallow region of the Laptev Sea eastwards of the fjord mouth is characterized with perennial pack ice and often calms, weak waves typically within 1 meter and relatively low convection in surface waters to the depth of only 5-10 meters. For most of the year the fjord and adjacent straits are covered with immobile fast ice, but even in winter, polynyas can be found at some locations seawards of the fjord, and the zone of landfast ice is relatively narrow. In general, the north-eastern coast of October Revolution Island appears to be less bounded with landfast ice than the western shore.

The regional climate influenced by continental air masses is one of the most severe in the Arctic. The longterm average air temperature is $-14.8{ }^{\circ} \mathrm{C}$, while the mean annual temperature of the past decade is $-11.8^{\circ} \mathrm{C}$ (Fig. 1, b). Mean annual precipitation, typically in the form of snow, is about $200 \mathrm{~mm}$ at sea level and 450 to $500 \mathrm{~mm}$ at higher altitudes. The climatic snowline altitude is at $50-100 \mathrm{~m}$, which is the lowest in the Eurasian Arctic. Six large ice caps cover $58 \%$ of the land area of October Revolution Island [8]. The mass balance of both parent ice caps is negative. In the past 25 years Karpinsky and Rusanov ice caps lost $21 \mathrm{~km}^{3}$ and $8.5 \mathrm{~km}^{3}$ of their volumes respectively [7]. There were no regular mass-balance measurements carried out in situ on the MIS surface.

The average sea surface temperature (SST) along the north-eastern coast of October Revolution Island is about $-0.8^{\circ} \mathrm{C}$. The medium layer with warm water at $+1.5^{\circ} \mathrm{C}$ originating from the inflow of Atlantic waters was revealed at $300 \mathrm{~m}$ depth. In warm summers numerous areas of open seawater surrounding MIS are found along ice-free coasts. The amplitude of local semi-diurnal irregular tides measures $0.3-0.4 \mathrm{~m}$, although it can surpass $1 \mathrm{~m}$ under strong NE winds [10]. Seasonal and inter-annual variations of the sea level recorded at the polar station on Golomyanny Island, 140 $\mathrm{km}$ westwards of MIS don't exceed $0.7 \mathrm{~m}$. Please refer to the maps in Figs. 2 and 6 hereafter, for all geographic locations, names and features.

\section{COLLECTED MAPS AND DATA}

Apart from remote sensing time series and stationary records, the most consistent, thorough and condensed factual knowledge on the MIS state and fluctuations is compiled in the form of maps and journal publications by Russian, British and American explorers. Yet, even our extensive collection contains very few detailed maps representing the entire MIS surface at large scale with sufficient accuracy (Fig. 2).
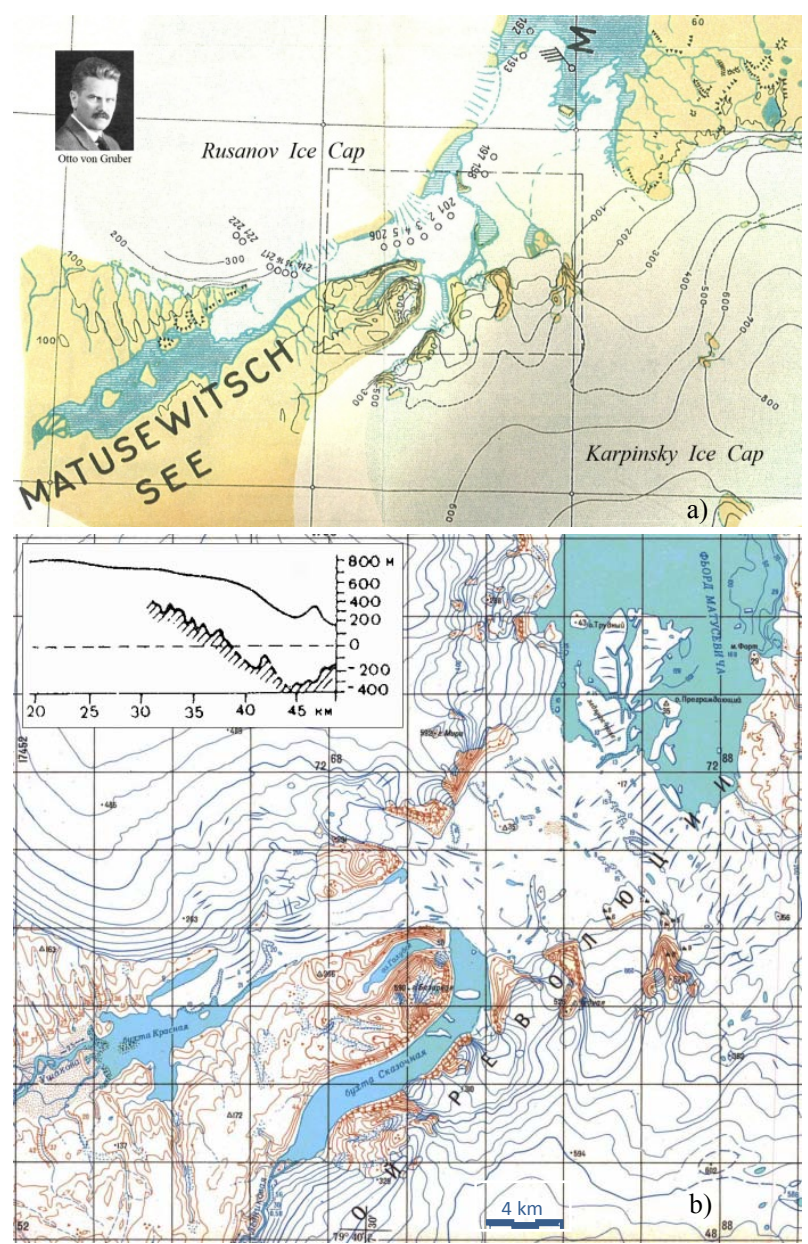

Figure 2. Photogrammetric maps of MIS: observational map 1:400, 000 by O.v.Gruber (1933, a); topographic map 1:200,000 $(1984, b)$ and RES profile (inset)

MIS was first explored and sketched by the expedition of G.Ushakov and N.Urvantsev during two sledge 
journeys across Matusevich Fjord in April-May and June-July, 1931. The first photogrammetric map showing the central part and marginal parts of the parent ice caps at 1:25,000 scale with a contour interval of 20 $\mathrm{m}$ and the observational map representing the entire MIS at 1:400,000 scale were produced by O.v.Gruber based on materials of the strip-wise stereoscopic photographic surveys performed from the airship Graf Zeppelin in July 1931 (Fig. 2, a).

The entire outlines of MIS were placed on a large-scale map after extensive air-borne photographic surveys of the entire archipelago had been carried out by the "Soyuzmorniiproject" Trust from 1951 to 1952. Airborne RES surveys of the ice shelf carried out in 1968/69 and 1973/74 allowed the ice thickness and glacier bed topography along MIS margins to be determined and mapped at small scales [8]. The next aerial photographic survey of MIS was performed in 1984 and provided basic materials for the present topographic map series of this glacier complex at scales $1: 100,000$ and 1:200,000 with contour intervals of 20 and $40 \mathrm{~m}$ (Fig. 2, b). The hydrographic chart No.11135 issued by the Russian Hydrographic Service in 1994 at 1:500,000 scale showing water depths in the Matusevich Fjord was also at our disposal. Up-to-date topographic maps and digital elevation models (DEMs) of the MIS area are either non-existent or of limited quality and coverage.

The space-borne interferometric radar data set covering MIS area included:

- two tandem ERS-1/2 SLCI pairs of 23/24.09.1995 and 22/23.03.1996. Both pairs were obtained from ascending orbits with normal baselines of $+5.5 \mathrm{~m}$ and $-46.2 \mathrm{~m}$ respectively under steady cold weather conditions with high atmospheric pressure, zero precipitation and spring tides;

- one TanDEM-X HH-SRA SM pair of 05.05.2011 obtained from ascending orbits with perpendicular cross-track baseline of $178.8 \mathrm{~m}$ (low atmospheric pressure of $996.8 \mathrm{mb}$, solid precipitation of 4 $\mathrm{mm}$ /day, spring tide);

- two repeat-pass Sentinel-1A Extra Wide Swath pairs (GRD and SLC) of 09/21.10.2014 (1017/1029 mb, zero precipitation and spring tides on both dates) and 06/18.12.2014 (1010/1024 mb, zero precipitation and neap tides on both dates) taken from ascending orbits with $\mathrm{B}_{\perp}=-70.9 \mathrm{~m}$ and single horizontal polarization;

- CryoSat-SIRAL SARIn interferometric altimetry data of $2010-2012$.

The space-borne optical data set included:

- 14 QuickBird and WorldView-1/2 quicklook images of 2009-2014;

- 8 LANDSAT images of 1973-2014;

- ICESat GLA06 lidar altimetry data (release 33) of 2003-2009. 30-year long records of hydrometeorological and oceanographic data obtained from 3 coastal stations (Golomyanny, Fedorova, and Vize) around MIS as well as ancillary glaciological and oceanographic publications were involved in the analysis of main causes and consequences of the MIS breakup.

\section{ICE SHELF MORPHOLOGY}

The entire ice catchment area of Matusevich Fjord was estimated at approx. $1100 \mathrm{~km}^{2}$ with $58 \%$ of the area belonging to Karpinsky Ice Cap. In [8] the total areas of outlet basins feeding MIS are given as $93.2 \mathrm{~km}^{2}$ and $179.5 \mathrm{~km}^{2}$ for Rusanov and Karpinsky ice caps respectively. RES surveys revealed that the northwestern periphery of Karpinsky Ice Cap rests on a bed located $150 \mathrm{~m}$ to $350 \mathrm{~m}$ below sea level and the tidewater glacier front is about $300 \mathrm{~m}$ thick [8]. The submerged part of the glacier bed is about $12 \mathrm{~km}$ wide (Fig. 2, b, inset). The outer south-eastern part of glacier bed of Rusanov Ice Cap is relatively flat and lies approximately at the sea level.

The very central part of MIS is surrounded with steep coasts descending east- and westwards and outlet glaciers flowing from Rusanov Ice Cap gradually merge without sharp distinction into the shelf ice, so that it is difficult to detect the ice shelf margin from the outside. Also at the right coast, the marked break in slope is not always detectable and precise delineation of the ice shelf area represents a challenging task. Most explorers draw inner shelf boundaries along the grounding line (point A in Fig. 3, a), where the shelf ice leaves land and begins to float. The projection of the grounding line on the ice shelf surface is above the geoid.
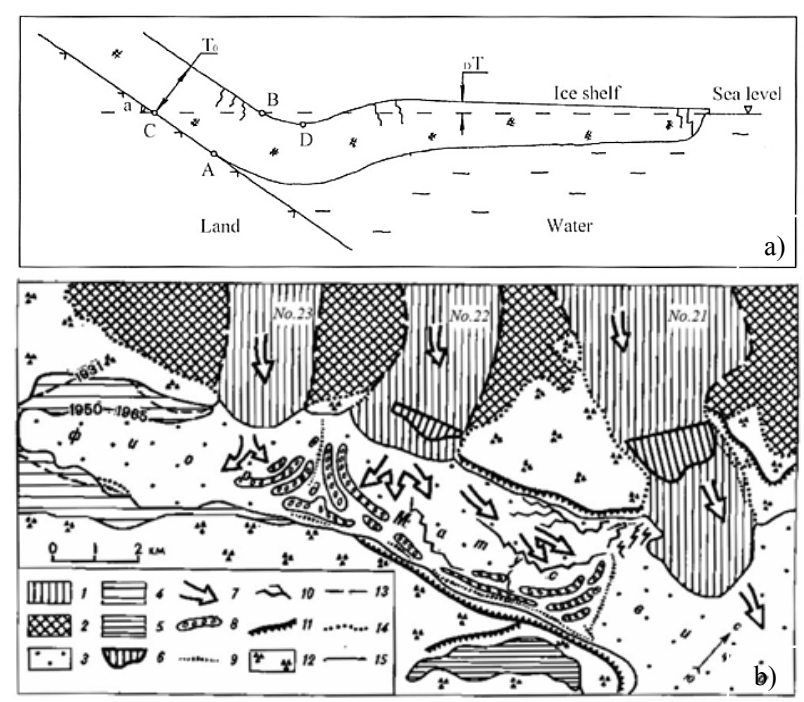

Figure 3. Inferred longitudinal profile (not to scale, a) and morphological scheme of MIS, inner part (b)

Both, the grounding line (A) and the coastline (C) hidden by ice masses flowing down into the fjord can be 
detected in radar interferometry data. Depending on the ice thickness $T_{0}$ and the glacier bed slope $\alpha$, wellexpressed hollows (D) can be seen rather often, but not necessarily, close to the boundary of the transitional zone (B). We observed such depressions in front of Khodov (No.21), AARI (No.48) and Researcher's (No.49) outlet glaciers. In general, the longitudinal profile of the ice shelf derived from hydrostatic equilibrium conditions and proved by our explorations in Franz Josef Land looks as shown in Fig. 3, a. Glacier numbers are given according to [8].

The MIS highest elevations range from 14 meters at the MIS front to 17 - 19 meters in the fjord centre and attain 21 meters in the innermost part, Red Bay (1984). Hence, the MIS maximum ice thickness can be estimated at 160 - 200 meters assuming hydrostatic equilibrium and using the buoyancy ratio of 0.105 . For the year 1984 the total MIS area was given as $217.2 \mathrm{~km}^{2}$ and the ice shelf volume was assessed at approx. $19 \mathrm{~km}^{3}$.

On closer examination the ice shelf morphology proves to be complex (Fig. 3, b, adopted from [6]). MIS elevations vary irregularly from several meters to several tens of meters at spatial scales of lesser than 1 $\mathrm{km}$. The ice thickness distribution and the ice flow pattern are also very heterogeneous. Floating glacier tongues coming in contact from opposite directions or striking against islands and coastal rocks create a succession of elongated ice rises and ridges rising up to 15-20 meters, which are well observed even in winter images. In summer, numerous shallow meltwater lakes and channels occur on the MIS surface, and depressions between ice bulges are typically filled with meltwater or rock debris. The same holds for large tabular icebergs. The total width of all outlets terminating in MIS measures 20 kilometres which is twice longer than the outer-fjord width of 8 to 10 kilometres. Numerous longitudinal fissures and crevasses on the surface of MIS and most of its tributaries indicate the compressive character of glacier ice flow in the fjord and especially at its flanks [9].

Considering the complexity of MIS morphology and variable dynamics we divided the ice shelf into three sections (Fig. 6), c.f. [4]. The inner part of MIS fed by outlet glaciers Nos. 21, 22 and 23 from the left and by outlet glaciers Nos. 46, 47 and 48 coming from the right is the most stable section of the ice shelf. This area covering approx. $80 \mathrm{~km}^{2}$ is referred to as MIS-A zone. The outer part named MIS-B is built by the ice from Researcher's Outlet Glacier (No.49) and is the most variable. The MIS-B section consists of three lobes, shaped like a shuttlecock, and transitional zone or "crown" between the ice shelf and the outlet glacier. The transitional zone of MIS-B with the area of about $25 \mathrm{~km}^{2}$ was first put on a map as the south-easternmost floating part of MIS by E.Zinger and V.Koryakin in
1965. Yet, it was not treated as a part of MIS in other cartographic publications. The third zone referred to as MIS-C covers the transitional zone between the ice shelf and Avsyuk Outlet Glacier (No.20) at the left coast of Matusevich Shelf. This narrow section with the area of approx. $4 \mathrm{~km}^{2}$ was represented as a part of MIS on Russian topographic maps and in [8], but was not considered as such in $[4,11]$.

\section{ICE SHELF ELEVATION MODELS}

The first cartographic MIS elevation model $\left(\mathrm{DEM}_{0}\right)$ with $50-\mathrm{m}$ posting was derived from the Russian topographic map 1:200,000 $(\mathrm{CI}=40 \mathrm{~m})$ showing the glacier state as surveyed in $1984 . \mathrm{DEM}_{0}$ represents parent ice masses and ice-free areas with sufficient accuracy and detailedness. The rms vertical accuracy of $\mathrm{DEM}_{0}$ is typically given as one fifth to one third of the contour interval on glaciers, i.e. 8 to $13 \mathrm{~m}$ rms. The information contents of available topographic maps showing, at best, only one contour line on the entire MIS surface and only one spot height per $10 \mathrm{~km}^{2}$ of the ice shelf area are obviously insufficient for representing the undulating character of the ice shelf surface. The direct use of the overall cartographic elevation model for glacier change detection and ice loss estimates is still limited, since it doesn't represent inner shelf borders and other structural elements, e.g. outlet glacier basins needed for glaciological measurements.

The mid-term interferometric elevation model $\left(\mathrm{DEM}_{1}\right)$ representing the MIS surface state of the 2000s was derived from the pair of differential ERS-1/2 SAR interferograms overlaid with ICESat GLA06 altimetry data (Release 33). Precise delineation of MIS area was manually performed using high-resolution optical imagery and the best interferometric coherence image of 23/24.09.1995 with a mean coherence value of 0,7 (Fig. 4, a). In complex cases, e.g. in the south-eastern confluent area, we additionally involved the second coherence image [c.f.12]. The representation of ice shelf elevations was essentially improved along and in the close vicinity of 17 altimetric transects crossing the MIS area with a track spacing of about $4 \mathrm{~km}$. The impact of long-term snow accumulation was neglected due to high rates of melting on the MIS surface. Yet, MIS elevations in between altimetric transects are errorprone due to data age difference and pronounced tidal effects on the DINSAR phase, especially in the central and eastern part of MIS. The rms vertical error of $\mathrm{DEM}_{1}$ was given as $\pm 4 \mathrm{~m}$ [7].

The present-day elevation model $\left(\mathrm{DEM}_{2}\right)$ with $25-\mathrm{m}$ posting applicable to the computer analysis of ice shelf characteristics and volume changes was generated from the TanDEM-X SAR interferometry data of 05.05.2011 and controlled using the concurrent CryoSat-2 interferometric radar and ICESat lidar altimetry data (Fig. 4, b). DEM 2 was further oriented by means of 
ground control points and was levelled by referencing to the landfast sea ice assuming the freeboard value of 0.25 $\mathrm{m}$. MIS is largely in the state of hydrostatic equilibrium and tides are relatively low. Hence the sea level recorded at the time of satellite surveys can be used as a datum plane for practical modelling of the glacier complex. The precision of elevation data checked on the northern fjord coast and at several ice-free islands with known heights was characterized by a rms vertical error of $\pm 2.7 \mathrm{~m}$. Topographic contour lines on the MIS surface were drawn at 10 meter intervals with the additional contour depicted at the elevation of $5 \mathrm{~m}$ (Fig. 4, b). Ice shelf areas with relatively thin ice were delineated in semi-automatic mode.

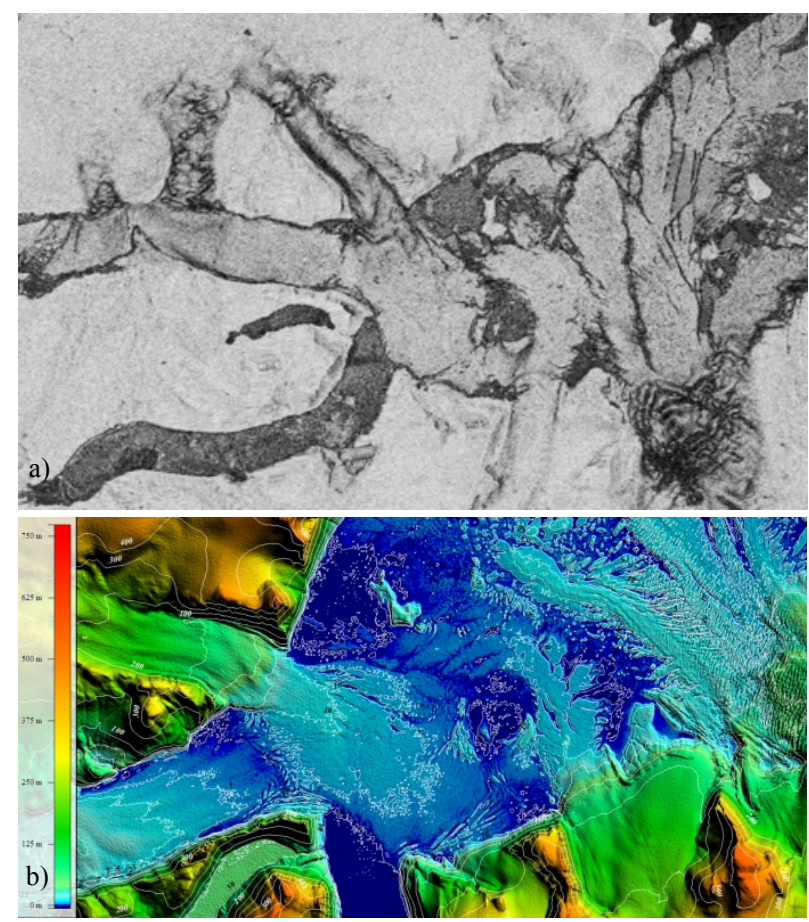

Figure 4. ERS-1/2 coherence image of 23/24.09.1995

(a); interferometric TDX DEM $\mathrm{DF}_{2}$ 05.05.2011(b)

The comparison with the cartographic $\mathrm{DEM}_{0}$ showed that the TDX elevation model is superior in representing top heights and lows, depicting ice surface undulations and compact glaciological features, such as ice ridges, depressions, crevasses etc., yet without compromising on positional accuracy. A dozen new islands underpinning the ice shelf were first discovered in $\mathrm{DEM}_{2}$ and, afterwards, verified in high-resolution optical images. In $\mathrm{DEM}_{2}$ we detected six elevated and crevassed ice shelf areas alternating with lower areas of thin even ice, apparently of marine origin. MIS top heights of up to $32 \mathrm{~m}$ asl are typically observed in front of tributary glaciers that feed into the ice shelf, while extensive areas of thinner ice with medial heights of several meters are to be found along ice-free coasts. The average elevation of the MIS sections was measured in $\mathrm{DEM}_{2}$ as $10.5 \mathrm{~m}$ (MIS-A) and $13.8 \mathrm{~m}$ (MIS-B), and the average ice thicknesses were given as $100 \mathrm{~m}$ and $131 \mathrm{~m}$ respectively. The expected maximum ice thickness of MIS was given as $220 \mathrm{~m}$ and the thickness of the thinnest parts was estimated at $25 \mathrm{~m}$. This observation sheds some light on spatiotemporal variations of the MIS iceberg production capacity.

\section{MAPPING ICE SHELF DIMENSIONS AND FLUCTUATIONS}

$\mathrm{DEM}_{2}$ was successfully applied to geocoding intermediate interferometric models, ortho-rectifying multitemporal optical and radar images from LANDSAT, WorldView, QuickBird and Sentinel satellites and building image time series. The image time series with the equalized pixel size of $50 \mathrm{~m}$ dating back to 1973 were attached with the vector layers derived from available maps representing the ice shelf boundaries in 1931, 1952 and 1984. Separate sections of the image time series were used for measuring ice shelf dimensions, quantifying ice loss processes, locating and dating main surging and calving events, and iceberg monitoring in the MIS area. Afterwards, they served as basic layers for the output map series and animations of the MIS evolution in 1931-2014 at $1: 100,000$ scale (UTM 46N, WGS84), which were included into the "Online atlas of glacier fluctuations" accessible at http://dib.joanneum.at/MAIRES/index.php?page=atlas. A small-size copy of one of maps demonstrating MIS disintegration is represented in Fig. 6.

The cartometric analysis of the resultant maps showed that the largest dimensions $\left(256 \mathrm{~km}^{2}\right)$ of the ice shelf were recorded at the very beginning of its explorations in 1931. Since then, MIS experienced several retreats in the 1950s and in the 1980s and advances in 1973 and in 1995 mentioned in [4]. Yet, the ice shelf area was never larger than that in 1931. After the last advance in 1995, the ice shelf retreated gradually. The essential acceleration of MIS disintegration was observed in the 2000s. The present MIS disintegration began no later than 2009 when the first large portion of the outer margin was lost. Finally, the ice shelf retreated from the shoal between Arduous and Barrier islands, split up into three unequal parts and lost two thirds of its original area of 1931 by late summer 2012. The ice shelf collapse continued in 2013-2014.

MIS event icebergs were mostly observed in 2010 and 2012 with surprisingly few large icebergs found in summers 2013 and 2014. In April 2010 we counted 14 large tabular icebergs of rhomboidal form wintering in the fjord. The largest iceberg was $2.77 \mathrm{~km}$ long and 1.42 $\mathrm{km}$ wide. Seven large tabular icebergs from the 2012 breakup were observed in the fjord in the fall of 2012 and in spring 2013. The largest of them were $3.3 \mathrm{~km} \mathrm{x}$ $1.0 \mathrm{~km}$ and $3.5 \mathrm{~km} \times 1.1 \mathrm{~km}$ in size, the latter was detected the inner fjord. The size of the largest iceberg sighted at the eastern coast of Severnaya Zemlya in 
August 2014 was 668 m x 336 m. Our observations showed that, in the past decade, the time between calving events varied from 1 to 2-3 years and the typical size of tabular icebergs might indicate the possible rate of ice flow at the glacier front. Hence, we supposed that the velocity of Researcher's Glacier exceeded 200 m/a.

The analysis of DINSAR and altimetry data showed that, in the period of 1984-2012, the MIS thickness decreased gradually in central and inner parts, and the ice surface roughness increased drastically over the past years. The maximum thinning up to $37 \mathrm{~m}$ was discovered in front of Polyarnikov Glacier with frontal velocity of less than $20 \mathrm{~m} / \mathrm{a}$ and between Khodov and Zhuravlev glacier tongues. According to $\mathrm{DEM}_{2}$, the present elevation of the ice shelf surface in both areas of extreme thinning does not exceed 2 and 3 meters respectively. The present minimal ice thickness of MIS was thus estimated at 25 meters.

The ice shelf dimensions in 1931-2014 are specified in Table 1. Large tabular icebergs attached, frozen or grounded close to the ice shelf were considered as a part of MIS. The total amount of ice loss from MIS due to calving, surface ablation and basal melting in the period of 1984-2012 is estimated at $13 \pm 0.4 \mathrm{~km}^{3}$. The advanceretreat cycles in the MIS observation history seem to be less regular than it was mentioned in [4, 13]. The present total area of MIS including MIS-A, MIS-B and MIS-C sections with "newly" detected floating area ("crown") in the south-eastern part of MIS-B was measured as $86 \mathrm{~km}^{2}$ (IX, 2014) and the remaining ice shelf volume was given as $6.4 \mathrm{~km}^{3}$, which is at least three times smaller than it was after the previous breakup in 1984-85. For the sake of data conformity the values given in Tab. 1 don't account for the presumably floating part $\left(\sim 25 \mathrm{~km}^{2}\right)$ between the ice front of MIS-B and the ice fault on Researcher's Outlet Glacier, $5 \mathrm{~km}$ upstream. Currently, the concave front-line of the MISB section runs between the glacier contour lines $40 \mathrm{~m}$ and $80 \mathrm{~m}$ represented in the Russian topographic map with the glacier state of 1984 . The present height of the MIS-B front ranges from $11 \mathrm{~m}$ in the east to $24 \mathrm{~m}$ in the west. The MIS-C section has nearly ceased to exist. Yet, several small icebergs were observed quite recently close to its southernmost front.

Our maps and quantitative estimates were verified and approved during the "Kara-Summer-2014" expedition to the Severnaya Zemlya archipelago on board the research vessel "Academician Treshnikov" under the leadership of A.V.Nesterov. Aerovisual observations and ice-sounding radar surveys of MIS remnants from a helicopter were carried out in August, 2014 and provided up-to-date ice thickness values ranging from 30 to 200 meters. The maximum ice thickness of $208 \mathrm{~m}$ was measured at the south-eastern MIS margin. In Red Bay, the maximal ice thickness of $155 \mathrm{~m}$ was recorded at the front of Zhuravlev Glacier. The ice fronts were found in the same position as they were represented in our maps. The average ice thickness of MIS remnants determined along reliable profiles was given as $75 \mathrm{~m}$. The value seems to have been underestimated and we suggest that it is not representative of the entire MIS. Due to the sparse coverage of the area by flight tracks, the absence of bottom returns over heavily crevassed areas, unstable weather and inaccurate referencing, the vertical accuracy of surveys was not better than $10 \mathrm{~m}$.

\section{ICE MOTION}

There are very few instrumental records documenting the rate of ice flow in the MIS region. Frontal velocities of several northern tributaries were measured in the field during the ablation season of 1965 . The resultant velocity diagrams with maximum velocity values ranging from $50 \mathrm{~m} / \mathrm{a}$ (Zhuravlev Glacier) to $110 \mathrm{~m} / \mathrm{a}$ (Khodov Glacier) can be found in Fig. 3, b). Although some relevant surveys using EO data are currently underway [13], the factual knowledge on ice flow velocities at the right coast of Matusevich Fjord remains extremely scarce.

Frontal velocities of 7 outlet glaciers flowing into the Matusevich Fjord were recently measured with the aid of satellite differential interferometry using ERS-1/2 INSAR data and the reference $\mathrm{DEM}_{2}$ (Fig. 5, a). It was reported that at least four outlets conveying ice to MIS from Rusanov Ice Cap, namely Khodov (No.21), Zhuravlev (No. 22), Esenin (No.23) and Researcher's (No.49) glaciers are fast flowing with frontal velocities exceeding $0.7 \mathrm{~m} /$ day or $170 \mathrm{~m} / \mathrm{a}$. This measurement indicates the essential acceleration of ice flow in the MIS area in the period of 1965-1995, but cannot be related directly to the breakup event of 2012, however. Further it was recognized that other small tributary glaciers are slow moving with frontal daily velocities ranging from 9 to $14 \mathrm{~cm} /$ day. Positive elevation changes up to $+29 \mathrm{~m}$ were detected in the accumulation zones of Fairytale (No.46) and Polyarnikov (No.47) outlet glaciers at the south-eastern coast of Fairytale Bay. Both glaciers are in a quiescent phase.

Table 1. Ice shelf dimensions in 1931-2014

\begin{tabular}{|l|c|c|c|c|c|c|c|c|}
\hline Year & 1931 & 1952 & 1973 & 1984 & 1995 & 2009 & 2012 & 2014 \\
\hline Area, $\mathrm{km}^{2}$ & 256 & 241.1 & 245 & 217.2 & 242 & 184 & 71.7 & 61.1 \\
\hline Length, $\mathrm{km}$ & 35.5 & 36 & 37 & 33 & 35 & 32.9 & 24.5 & 23.7 \\
\hline Volume, $\mathrm{km}^{3}$ & - & $\sim 22$ & - & $\sim 19$ & - & $\sim 15$ & - & $\sim 6$ \\
\hline Source & {$[6,9]$} & {$[8,11]$} & {$[4,7]$} & {$[7]$} & {$[7]$} & {$[7]$} & Present & Present \\
\hline
\end{tabular}



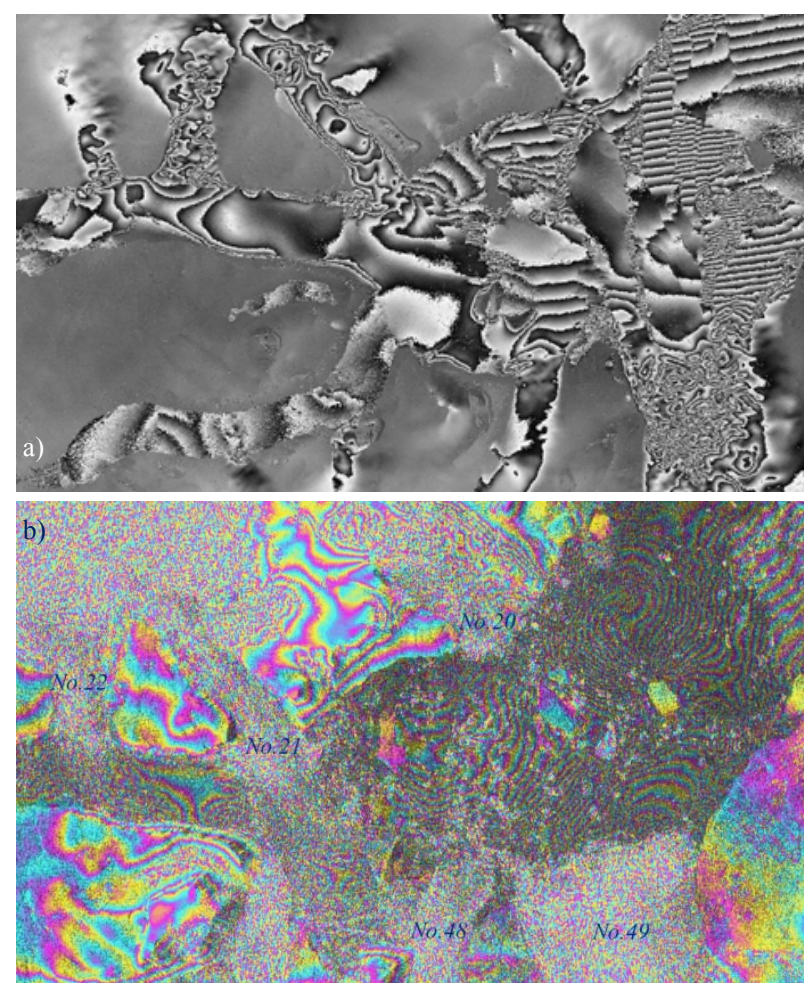

Figure 5. MIS: ERS-1/2 DINSAR model of 23/24.09.1995

(a) and S1A EW3 fringe image of 06/18.12.2014 (b)

The replacement of $\mathrm{DEM}_{0}$ with $\mathrm{DEM}_{2}$ treated in this paper improved the accuracy of DINSAR measurements and showed that the daily velocity of ice flow in the middle part of Researcher's Glacier at a distance of 5 $\mathrm{km}$ from the glacier front was $0.5 \mathrm{~m} /$ day or $120 \mathrm{~m} / \mathrm{a}$. The velocity of glacier flow increases notably downstream and the maximum velocity value close to the glacier front is supposed to be about $200 \mathrm{~m} / \mathrm{a}$. This glacier demonstrates steadily extending character of ice flow with predominantly transverse crevasse pattern. Besides, we recognized that the character of ice flow on Zhuravlev, Esenin and AARI glaciers changed from compressive to extending and the crevasse pattern changed correspondingly from longitudinal to transverse.

The interferometric measurement of ice flow velocities with the aid of Sentinel-1 SAR data was limited by the 12-day repeat interval of satellite surveys, relatively low coherence and significant phase noise on radar interferograms of fast flowing tributaries (Fig. 5, b). We detected several patches with good visibility of S1 interferometric fringes in the inner part of MIS and recognized that these spots coincided with the areas of thinner shelf ice between glacier tongues. We suggest that the ice shelf undergoes tide-induced vertical oscillations in some parts with thinner ice as a plausible explanation for such finding. The S1 INSAR data of 06/18.12.2014 shows an extensive area of fast sea ice attached to the fronts of MIS-A, MIS-B and MIS-C sections. The frontal velocity of the eastern lobe of Researcher's Glacier was estimated at approx. $100 \mathrm{~m} / \mathrm{a}$ by analysing the fast-sea-ice motion induced by glacier flow. The maximum glacier velocity at the centre of the glacier front was determined as being close to $200 \mathrm{~m} / \mathrm{a}$ under the assumption that it is twice of that at the flank. The analysis of concentric tide-related fringes proved the existence of a shoal $(50 \mathrm{~m}$ bsl) located half way between Arduous and Barrier islands.

\section{CAUSAL ANALYSIS AND CONCLUSIONS}

In 2009, MIS front retreated from the shallow water area between Arduous and Barrier islands and the ice shelf disintegrated rapidly during the next 5 years. Rapid climatic warming in the High Arctic is the most obvious reason for the MIS disintegration in 2009 2014. A general negative balance of parent ice masses was related to the climatic changes too [7]. The 2012 breakup of MIS is the largest glacier calving ever reported from the Russian High Arctic. The annual rate of ice loss from MIS given as $0.43 \mathrm{~km}^{3} / \mathrm{a}$ has yet to be accounted for in the long-term mass balance research in Severnaya Zemlya. We suggest that the rate of total ice loss due to calving and basal melt in Severnaya Zemlya previously specified in $[7,8]$ is out-of-date and must be revised.

The main causes of the MIS breakup are summarized as follows. The leap-year 2012 was the warmest and the wettest in the history of meteorological observations at the Golomyanny station. The mean annual temperature of $-9.3^{\circ} \mathrm{C}$ recorded in 2012 reached practically the threshold of $-9^{\circ} \mathrm{C}$ specified as climatic limit for the iceshelf viability in [5]. In 2012 the annual precipitation amount in Severnaya Zemlya reached the record value of $353 \mathrm{~mm}$. The number of days with rain (61) was twice larger than the long-term average value. Rains with the intensity of up to $25-27 \mathrm{~mm} /$ day destroyed the snow cover on the MIS surface in June-September and, together with extensive meltwater on the ice-shelf surface, contributed essentially to fracturing processes. There were a series of severe storms with wind gusts up to $104 \mathrm{~km} / \mathrm{hr}$ and surges recorded at Golomyanny and Fedorov meteorological stations in April-July 2012. Very similar climatic records were registered at the Vize station $400 \mathrm{~km}$ westwards of MIS.

In past years, SSTs in the northern Laptev Sea in August were several degrees warmer than the 19822010 August mean [14]. The inflow of warm surficial and medium-layer waters into the Matusevich Fjord and enhanced basal melting of the ice shelf is believed to be one of the main causes for the ice shelf disintegration and iceberg removal from the fjord. The high rate of MIS thinning given as $1.3 \mathrm{~m} / \mathrm{a}$ can be directly associated with basal melting of MIS. The increase in pre-event velocities of MIS tributaries, the transition to extending 
ice flow, and structural weakening of the ice shelf might impact its reaction to climatic forcing in the 2010s. We suggest that the buttressing resistance of the ice shelf decreases with the ice thickness well before the removal of shelf ice from the fjord.

It was decided that the unfavourable combination of long-term atmospheric and oceanic warming, heavy precipitation in liquid form and strong winds in summer as well as essentially negative mass balance of both parent ice caps, structural weakening of the ice shelf and, probably, low concentrations of sea ice along the eastern coast of Severnaya Zemlya was the main driving factor for the MIS event in 2012. Based on the seismic history of the Laptev Sea, we excluded nonrecurring one-time impacts, such as earthquakes and tsunami from the causal analysis of the breakup. We suppose that, under current environmental conditions, MIS-A and MIS-B sections will vanish within the next decade. Several areas with thin ice in the MIS-A section will disappear first, followed by floating tongues of Esenin, Zhuravlev and Khodov glaciers. The potential advance of several smaller tributary glaciers having a positive mass balance can decelerate MIS recession, but cannot stop it. The Researcher's Glacier will continue calving and will likely undergo further retreat which will stop when the glacier front reaches a new stable position, 7 to $8 \mathrm{~km}$ upstream from the present location.

Thanks to the wide terrestrial coverage of Sentinel-1 EWS data, we were able to compare the rate of MIS disintegration with the concurrent ice loss rates from two smaller ice shelves in Severnaya Zemlya, No.19 at the eastern margin of Academy of Sciences Ice Cap and No.70 at the southern margin of Karpinsky Ice Cap situated $70 \mathrm{~km}$ to the north and $60 \mathrm{~km}$ to the south of MIS respectively. The areas of these ice shelves were measured in the $1950 \mathrm{~s}$ as $5.7 \mathrm{~km}^{2}$ and $11.1 \mathrm{~km}^{2}$ respectively [8]. To our surprise, we discovered that the ice shelf No. 19 advanced and its area increased by 2.2 $\mathrm{km}^{2}$ (2014). We explained this finding by the local dynamics of the Academy of Sciences Ice Cap, colder climate and the temporary excess of ice masses in the upper part of this glacier mentioned in [7]. The ice shelf No.70 built by two confluent outlet glaciers Nos. 66 and 67 on Karpinsky Ice Cap calves in fresh-water Fjord Lake with the bathymetric mark of $98 \mathrm{~m}$ close to the outer shelf margin with an elevation of $6 \mathrm{~m}$ (1984). There is some doubt on the floating state of this glacier. The glacier area measured in the WV02 optical image of 2013 does not exceed $9 \mathrm{~km}^{2}$, which means a relative decrease of $20 \%$ in approx. 30 years.

Finally, we conclude that the rapid collapse of MIS is a new sign of climate change in the Eurasian High Arctic and is consistent with the observations made recently in the Canadian Arctic and Greenland, where large ice shelves demonstrate similar behaviour. The mean annual temperature of $-9^{\circ} \mathrm{C}$ proved to be a valid climatic threshold for the ice-shelf viability in the High Russian Arctic. We expect an essential improvement of glacier interferometric models with the advance of Sentinel-1B satellite and anticipate further use of our products by Russian colleagues for operational iceberg monitoring in the Kara-Laptev region.

\section{ACKNOWLEDGEMENTS}

The present study was funded from the EuRuCAS FP7 INCO project. ERS, CryoSat-2 and TanDEM-X satellite data were provided by ESA and DLR through AOP.6327 GEMINI and AOP.GLAC249 GEODESIA. S-1A SAR EW data were obtained from the Sentinel-1 Scientific Data Hub. ICESat altimetry data were made available by NSIDC. Hydrometeorological data were downloaded from the "TuTiempo" online archive of historical weather.

\section{REFERENCES}

1. Dowdeswell, J. et al. (1994). Evidence for floating ice shelves in Franz Josef Land, Russian High Arctic. AAR. 26 (1), 86-92.

2. Münchov, A. et al. (2014). Interannual changes of the floating ice shelf of Petermann Gletscher, North Greenland, from 2000 to 2012. J. Glac. 60(221), 13 J135.

3. Copland, L. et al. (2007). Rapid loss of the Ayles Ice Shelf, Ellesmere Island, Canada. GRL, 34 (L21501), doi: 10.1029/2007GL031809.

4. Williams, M. \& Dowdeswell, J. (2001). Historical fluctuations of the Matusevich Ice Shelf, Severnaya Zemlya, Russian High Arctic. AAAR, 33 (2), 211-222.

5. Morris, E. \& Vaughan, D. (2003). Spatial and temporal variation of surface temperature on the Antarctic Peninsula and the limit of viability of ice shelves. Antarctic research series, Washington, AGU, 61-68.

6. Govorukha, L.S. (1989). Modern glaciation of the Soviet Arctic. Leningrad, Gidrometeoizdat, $256 \mathrm{p}$.

7. Sharov, A. \& Tyukavina, A. (2009). Mapping and interpreting glacier changes in Severnaya Zemlya with the aid of differential interferometry and altimetry. ESA SP-677, 8 p.

8. Vinogradov, O.N. (1980). Catalogue of glaciers on Severnaya Zemlya. Hydrometeoizdat, L., 79 p. (in Russ.)

9. Gruber, O. (1933). Über die Ausrüstung des "Graf Zeppelin“, die Auswertungsmethoden und die bisherigen Ergebnisse aus dem gewonnenen Aufnahmematerial. Petermanns Mitteilungen. Gotha, 216, 68-77.

10. Gorshkov S.G. (1980). Atlas of the Arctic Ocean. Leningrad, GUNO, $188 \mathrm{p}$.

11. Koryakin, V.S. (2014). What is happening to Severnaya Zemlya's glaciers? Nature, 11, $42-49$ (Russ).

12. Rignot, E. et al. (2011). Antarctic grounding line mapping from differential radar interferometry. GRL, 38 (L10504), doi: 10.1029/2011GL047109.

13. Willis, M.J. et al. (2013). Outlet glacier thickness and velocity changes in response to the destruction of the Matusevich Ice Shelf. AGU Fall Meeting, \#C13D-07.

14. Timmermans, M. \& Proshutinsky, A. (2014). Arctic Ocean surface temperature. Arctic Report Card: Update for 2014. DOC, NOAA, 3 p. 


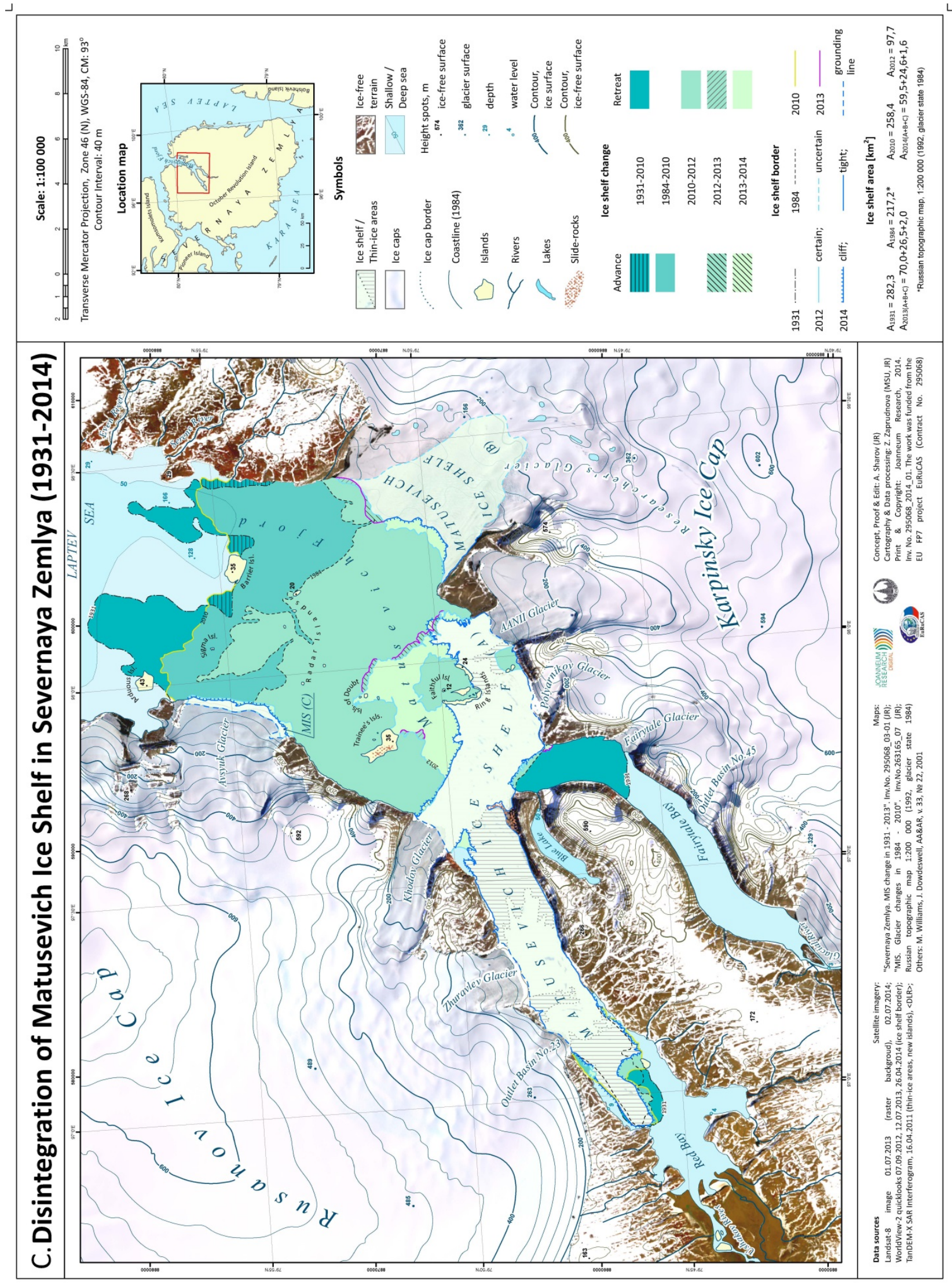

Figure 6. Satellite image map 1:100,000 of MIS evhandleolution in 1931 - 2014 